\title{
SALUTOGENIC IMPACT OF SOCIAL CAPITAL ON HEALTH; A STUDY IN PUNJAB, PAKISTAN
}

\author{
Zarqa Azhar \\ Lecturer, Department of Sociology \& Criminology, University of Sargodha, Pakistan \\ zarqazhr@gmail.com \\ Yasir Nawaz Manj \\ Associate Professor, Department of Sociology \& Criminology, University of Sargodha, Pakistan \\ yasir.nawaz@uos.edu.pk \\ Falak Sher \\ Director, Institute of Arts and Sciences, GC University Faisalabad (Chiniot Campus), Pakistan \\ Falaknnawaz@hotmail.com

\begin{abstract}
Every society is very much concerned about the health of individual because it links with the development and progress of that society.in this domain social capital is a very strong resource of society in health promotion. Using a sample of 400 respondents this study aimed to find out the impact of different dimensions of salutogenic social capital on health. This research used a quantitative research design and household survey was conducted to collect data. A well-structured self-administrated questionnaire was used as a tool for data collection. Sample was obtained through multi-stage sampling technique and the process of data collection was completed in 2014 and data analysis completed in 2015. Findings of this research revealed positive association between social capital (groups and networking) and health of respondents.
\end{abstract}

Key words: Social capital, groups and networks, social cohesion, health

\section{INTRODUCTION}

Social capital gained much popularity in the 21st century when it entered in the mainstream of scientific discourse and becomes most popular in the discussions of social policy and researchers (Song, 2013). Social capital is an indicator of community cohesiveness which helps to understand the wellbeing of the people (Kunitz,2004). The concept of social capital is defined as social resource which is used for the development and betterment of society (Fujiwara\& Kawachi,2008). Despite the fact that the measurement of social capital still having a lot of debate, there is general consensus that social capital is an asset not only for the individuals but also for the community and influencing their social well-being (Eriksson, 2011).

In last two decades, researchers have extensively investigated the impact of social capital on physical and mental health. Social capital is a powerful factor in shaping opinions and behaviors and affecting different areas of public life (Durst, Viol, \& Wickramasinghe,2013). People who are attached to a social network enjoy a lot and these social networks are the form of a social capital and effects of these associations whether are negative or positive mostly visible on those who are more deeply integrated in the community (Fujiwara \& Kawachi, 2008; Eriksson, 2011).

In a social structure, social capital is gained as an outcome of social relationships. Social networks are tied with a flow of resources, both material and non-material (Williams \& Durrance, 2008). The resources may include social support, emotional support, informational support, companionship, time, information, money, business transactions or shared activity. Social capital emerges from the social interaction and the norms which are shared and all they are external to individuals. This phenomenon is collective in nature, a public good which enables the condition of the other considerable public goods (Ryan, Sales, Tilki, \& Siara, 2008) and outcomes of action will be increased by the resources that are embedded in the social networks. It facilitates the flow of information and exerts influence on the agents. These agents play a significant role in decision making and provide access to the resources the individual and at last they are expected to strengthen the recognition and identity (Lin, 1999). 
Roots of social capital was found in the work of Durkheim, De Tocqueville and Marx but development of the social capital concept and further articulating its link with health are the struggles of three main proponents different sociologists including Pierre Bourdieu, US political Economists etc have given its definition differently and they have added different theoretical facets to the social capital concept. Bourdieu defines this term in terms of interpersonal relationships and networking. According to Bourdieu individuals are linked through networks, product of gathering of exchange, responsibilities and shared identities for the sake to access to resources and potential support. Product of gathering of exchanges, responsibilities and shared identities that provide potential support in return and access to resources (Morgan \& Swann, 2004).

Conventionally the concept of social capital took to include two factors, one of them is affiliation's network affiliation groups including, formal and informal groups, primary and secondary groups, secondly the informal behavioral values and norms on which individual and groups are dependent while maintaining, establishing and while using that norms. In those norms behaviors like reciprocity and trust are included and self-identity is also included as interpretive components (Bexley, Marginson, \& Wheelahan, 2007). The combination of social norms of reciprocity, networks and trust make social capital. It is a sort of resource which can be accessed through social networking. The basic idea of social capital according to the Putnam shared values, interrelationship between people and group productivity (Fujiwara \& Kawachi, 2008; Ferlander, 2007).

\section{Study objectives}

The objectives of this research were to identify the socio-economic and demographic attributes of the respondents and to explore the effect of grouping and networking on the health of individuals. Another objective was to identify the effect of social cohesion and inclusion in the community with the health and to describe the relationship between information and communication with health of individuals in the community.

\section{REVIEW OF LITERATURE}

Health and our social ties related to each other because health is not an isolated phenomenon. It not only effected by the attack of any pathogen rather than our social conditions also have various effects on its different dimensions. Social capital refers to the various bonds that hold communities together, and is more likely to present wherever there is a sense of belongingness and support, trust, shared goals, social networks and group affiliations. It is evident in volunteerism and civic participation. Social capital consists of active connections among people, the mutual understanding, shared values, trust and the behaviors that tie the individuals, communities and human networks and make cooperative action possible between them (Hodgetts, et al., 2010).

According to the Chuang, Chuang, \& Yang (2013) study the concept of social cohesion and develop measurement scale for measuring this concept and also examine the association between social cohesion and individual health. results of this research revealed that countries who had more social inclusion, diversity and capital were more expected to report good health status. In another research Giordano, Merlo, Ohlsson, Rosvall, \& Lindström (2013) explain the relationship between social capital and health. Research used data from the United Kingdom's British Household Panel Survey $(\mathrm{N}=6982)$, this longitudinal, multilevel study investigates the validity of the association between trust, social participation and self-rated health using a family-based design. Results of this research revealed that the association between social participation and self-rated health was fully satisfied. Forsman (2012) examine the importance of social capital in later life. The main objective of this research was to examine the association between mental ill-health and social capital among older adults as well as to collect and evaluate the effect of psychosocial interventions for the primary prevention of depressive disorders. Results of this research indicates that restricted social networks with regard to both quantity and quality aspects were found to associate with depression and psychological distress in later.

\section{Conceptual Framework}

\begin{tabular}{|l|c|c|}
\hline Background & Independent & Dependent \\
\hline Age & Social capital & Health \\
\hline Gender & Groups and Networks & Physical health \\
\hline
\end{tabular}




\begin{tabular}{|c|c|c|}
\hline Education & $\begin{array}{l}\text { Information and } \\
\text { Communication }\end{array}$ & Mental health status \\
\hline Marital status & Social Cohesion and Inclusion. & Nutritional status \\
\hline Family structure & & \multirow[t]{4}{*}{ Health seeking behavior } \\
\hline Family income & & \\
\hline Occupation & & \\
\hline Residential Area & & \\
\hline
\end{tabular}

This research used the above conceptual framework to understand the impact of social capital on the health of individual. This research used groups and networking, information and communication and social cohesion and inclusion as the indicator of social capital and took them as independent variables. Health of individual is dependent variable and physical health, mental health, nutritional status and health seeking behavior were its indicators.

\section{RESEARCH METHODOLOGY}

This study employed a quantitative research design. Household Survey method is used for this research and data were collected through a well-structured questionnaire from the respondents. In this research 400 respondents were selected through multistage sampling techniques and the process of data collection completed in 2014. Data analysis was comprised of descriptive statistics for UniVariate analysis and inferential statistics for bi-variate analysis. In bi-variate analysis, chi-square test was used to find associations and gamma test was employed to measure and analyze the strength and direction of relationship between independent variables and dependent variable. Pakistan is comprised on four provinces. Punjab is the big province according to the population size. Researcher selected Punjab province for this research conveniently because researcher also belongs to this province and from its nine divisions, in first stage four divisions (Sargodha, Faisalabad, Multan and Gujranwala) were selected through random sampling technique. In second stage from each division one district (Khushab, Multan, Faisalabad, and Gujranwala) was selected through simple random sampling technique. At third stage from four districts one Tehsil (Khushab from Khushab, madina town from Faisalabad and kamoki from Gujranwala, Jalalpur Piranwala from Multan) was selected from each Tehsil and at fourth stage three union councils were selected from each Tehsil through proportionate sampling technique. At fifth stage areas from each union council were selected through convenient sampling technique. At sixth stage through systematic sampling technique respondents were selected. Researcher selected interval of 10 for systematic sampling. Before filling the questionnaire, respondents were provided a form of informed consent in which their confidentiality and anonymity was assured. This study was approved by the ethical review board, department of sociology and criminology, university of Sargodha.

\section{RESULTS AND DISCUSSION}

Table No. 1: Socio-demographic and economic information of respondents

\begin{tabular}{|c|c|c|c|c|c|}
\hline Gender & Frequency & Percentage & $\begin{array}{l}\text { Family } \\
\text { Structure }\end{array}$ & Frequency & Percentage \\
\hline Male & 196 & 49.0 & Nuclear & 155 & 38.8 \\
\hline Female & 204 & 51.0 & Joint & 225 & 56.3 \\
\hline Age & & & Extended & 20 & 5.0 \\
\hline $18-28$ & 206 & 51.5 & Family income & & \\
\hline $29-38$ & 95 & 23.8 & less than 10,000 & 42 & 10.5 \\
\hline $39-48$ & 45 & 11.3 & $11,000-24,000$ & 76 & 19.0 \\
\hline $49-58$ & 44 & 11.0 & $25,000-40,000$ & 137 & 34.3 \\
\hline above 59 & 10 & 2.5 & $41,000-54,000$ & 75 & 18.8 \\
\hline Education & & & $\begin{array}{l}55,000 \text { or above } \\
\text { it }\end{array}$ & 70 & 17.5 \\
\hline Illiterate & 15 & 3.8 & Occupation & & \\
\hline Primary-Middle & 29 & 7.3 & Govt. employee & 58 & 14.5 \\
\hline Matric-Intermediate & 68 & 17.0 & Private employee & 188 & 47.0 \\
\hline
\end{tabular}




\begin{tabular}{|l|l|l|l|l|l|}
\hline B.A-M.A & 265 & 66.3 & Agriculture & 37 & 9.3 \\
\hline MPhil/PhD & 23 & 5.8 & Businessman & 33 & 8.3 \\
\hline Total & 400 & 100.0 & Others & 84 & 21.0 \\
\hline Marital Status & \multicolumn{7}{|l|}{} & Residential Area & & \\
\hline Single & 229 & 57.3 & Urban & 291 & 72.8 \\
\hline Married & 162 & 40.5 & Rural & 109 & 27.3 \\
\hline Widow/Divorce & 9 & 2.3 & Total & $\mathbf{4 0 0}$ & $\mathbf{1 0 0 . 0}$ \\
\hline
\end{tabular}

Above table shows that a little more than half of the respondents were females while the males were $49 \%$. Majority of the respondents were lying in the age category of $18-28$. This table describes that educational status of the respondents. A majority of the respondents (66.3\%) were with education level from graduation to masters. A majority of the respondents were single. Family income is also a main determinant of socioeconomic status. About $69 \%$ respondents had 25 thousand or above monthly income. 72.8 respondents belonged to urban areas.

\section{Testing Of Hypotheses}

Hypothesis no 1. Strong bonds in grouping and networking leads toward the better health status of the individuals.

Hypothesis no 2. There is association between the information and communication in society and better health status of the individuals in society.

Hypothesis no 3: More the social cohesion and inclusion in society better will be the health condition of the individuals of the society.

Table 2 presents the association between the groups and networking and the health status of the respondents. The value of Pearson chi-square (30.21) shows the significant relationship between the groups and networking and health status of the respondents. Likelihood Ratio, Linear by Linear Association and Gamma tests show a positive relationship between variables. Findings revealed that respondents who had moderate level of grouping and networking had better health status. So the hypothesis that "Strong bonds in grouping and networking leads toward the better health status of the individuals" has been accepted. Although the cross-table has shown interesting results that the best health conditions can be found where the level of social interaction is moderate. Association between the information and communication and the health status of the respondents is also presented. The value of Pearson chi-square (16.561a) shows the significant relationship between the information and communication and health status of the respondents. Respondents who had low information and communication $(17.35 \%)$ had worse health status, $(70.40 \%)$ had moderate while $(12.24 \%)$ had better health status. So, the hypothesis that "There is association between the information and communication in society and better health status of the individuals in society" has been accepted.

Table No. 2: Chi-Square and Gamma values showing relationship between independent variables and Health status of respondents

\begin{tabular}{|l|l|l|l|l|l|}
\hline Variable name & $\begin{array}{l}\text { Chi-square } \\
\text { value }\end{array}$ & $d . f$ & Significant & $\begin{array}{l}\text { Gamma } \\
\text { value }\end{array}$ & Significant \\
\hline Groups and networks & $30.218^{\mathrm{a}}$ & 6 & .000 & .314 & .002 \\
\hline Information \& communication & $16.561^{\mathrm{a}}$ & 8 & .035 & .182 & .068 \\
\hline Social cohesion \& inclusion & $10.414^{\mathrm{a}}$ & 6 & .108 & .214 & .049 \\
\hline
\end{tabular}

Above table also presents the association between the social cohesion and inclusion and the health status of the respondents. The value of Pearson chi-square (14.414) shows the significant relationship between the social cohesion and inclusion and health status of the respondents. Above table also shows that respondents who had low social cohesion and inclusion in the society $(17.1 \%)$ had low health status, $(72.36 \%)$ had moderate while $(10.52 \%)$ had high health status. Findings of above table also revealed that respondents who had moderate level social cohesion and inclusion (9.09\%) had low health status, $(76.72 \%)$ had moderate while $(14.18 \%)$ had high health status and findings also shows that respondents who had high level of grouping and networking (12.24\%) report low health status, $(67.34 \%)$ had moderate while $(20.4 \%)$ had high health status. So, the hypothesis that "more the social cohesion and inclusion in society better will be the health condition" has been accepted. 


\section{DISCUSSION}

The present study on social capital, health behaviors and health status among adults found that social capital is clearly associated with better health status irrespective of socio-demographic and economic characteristics. This study found that respondents who had low groupings and social networking in the society, they had worse health status while those who have greater social networking, have better health status. These findings are consistent with previous studies which narrated that family social capital was significantly associated with health of individuals and social capital act as a buffer against the mental health of individuals (Kunitz, 2004; Magson, Craven, \& Bodkin-Andrews, 2014). In addition, this study has found a significant relationship of the provided information and communication with the health status of the respondents. It was found that the respondents who had low informational support and communication, they had worse health status. Recent research has also confirmed that the higher the level of informational support, the greater the likelihood of better health (Bukhari, 2020; Lee, Lin, \& Wu, 2020). Furthermore, this study found a significant relationship between the social cohesion and inclusion and health status of the respondents. Respondents with more social cohesion showed better health status. Respondents with more inclusive relationships also showed better health status. The observed associations between the social cohesion and inclusion and health status confirm earlier findings which narrated in their findings of research that respondents from those countries where high social cohesion and inclusion found healthier (Chuang, Chuang, \& Yang, 2013; Berkman, 2000). Pakistani society has a collectivistic culture which helps people to have more social capital networks. This study has revealed that a conscious effort by people to build and strengthen an interpersonal bond with people can improve their subjective well-being and overall health condition.

\section{CONCLUSION}

Present research aimed to explain the relationship between the social capital and health and the study also find out the influence of different type of social capital on health of individuals and the main hypotheses of this research were greater the amount of contact with others greater will be the health condition and another hypothesis was more the social cohesion and inclusion in society better will be the health condition. Findings of present research revealed groups and networking had impact on people's health status and the social cohesion and inclusion also had the same impact on the health condition of the respondents. So, research concluded that social capital is a capital which resides in the social ties of individuals and this capital had very strong link with their health status and its dimensions bonding and bridging were associated with the physical, mental and nutritional health status and also with the health behaviors of individuals.

\section{SUGGESTIONS}

Social capital is a very strong resource found in society which has salutogenic impact on the health of individual. So the government and local community can utilized this capital in different projects of health and especially creating awareness through it.

Community can promote health seeking behavior through social capital of society because people in group have more tendency to follow its norms. So health authorities can use groups as a resource for mobilization.

This can also promote the environment of hygiene if people sensitized at their group level. We can disseminate awareness information about many diseases and treatments through the help of social capital of that community.it can also involve the local community and include them in health promoting projects.

\section{Strengths and Limitations of the Study}

The present study has provided a significant insight of the salutogenic effect of social capital on health. The findings of the current study extend the academic scholarship on social capital in healthcare. There are a few limitations of this study. This study was restricted to respondents in only one setting. Although it used a sample of 400 respondents, it cannot be generalized. 


\section{REFERENCES}

Berkman, L. F. (2000). Social support, social networks, social cohesion and health. Social work in health care, 31(2):3-14.

Bexley, E., Marginson, S., \& Wheelahan, L. (2007). Social Capital in Theory and Practise. Melbourne: Centre for the Study of Higher Education, The University of Melbourne.

Bukhari, S. R. (2020). Perceived social support and quality of life among patients with psychiatric disorders. Rawal Medical Journal, 45(3):554-6.

Chuang, Y. C., Chuang, K. Y., \& Yang, T. H. (2013). Social cohesion matters in health. International journal for equity in health, 12(1):1-2.

Durst, C., Viol, J., \& Wickramasinghe, N. (2013). Online social networks, social capital and healthrelated behaviors: a state-of-the-art analysis. Communications of the Association for Information Systems, 32(1):5.

Eriksson, M. (2011). Social capital and health-implications for health promotion. Global health action, 4(1):5611.

Ferlander, S. (2007). The Importance of Different Forms of Social Capital for Health. ActaSociologica, 115-128.

Fujiwara, T., \& Kawachi, I. (2008). Social capital and health: a study of adult twins in the US. American journal of preventive medicine, 35(2):139-44.

Hodgetts, D., Drew, N., Sonn, C., Stolte, O., Nikora, L. W., \& Curtis, C. (2010). Social Psychology and Everyday Life. New York: Palgrave Macmillan

Kunitz, S. J. (2004). Social capital and health. British medical bulletin, 69(1):61-73.

Lee, J. K., Lin, L., \& Wu, X. V. (2020). Social Capital and Health Communication in Singapore: An Examination of the Relationships between Community Participation, Perceived Neighborliness and Health Communication Behaviors. Journal of Health Communication, 25(4):323-32.

Lin, N. (1999). Building a network theory of social capital. Connections, 22(1):28-51.

Magson, N. R., Craven, R. G., \& Bodkin-Andrews, G. H. (2014). Measuring Social Capital: The Development of the Social Capital and Cohesion Scale and the Associations between Social Capital and Mental Health. Australian Journal of Educational \& Developmental Psychology, 14:202-16.

Morgan, A., \& Swann, C. (2004). Social capital for health: issues of definition, measurement and links to health. Health Development Agency.

Ryan, L., Sales, R., Tilki, M., \& Siara, B. (2008). Social networks, social support and social capital: The experiences of recent Polish migrants in London. Sociology, 42(4):672-90.

Song, L. (2013). Social capital and health. In Medical Sociology on the move (pp. 233-257). Springer, Dordrecht.

Williams, K., \& Durrance, J. C. (2008). Social networks and social capital: Rethinking theory in community informatics. The Journal of Community Informatics, 4(3). 